\title{
Cardiac myocyte functional and biochemical changes after hypothermic preservation in vitro
}

\author{
Protective effects of storage solutions
}

In this study, we evaluated cardiac myocyte viability and function under hypothermic conditions with four types of storage solutions. saline solution, Euro-Collins solution, University of Wisconsin solution, and MCDB 107 medium. Cardiac myocytes were isolated from neonatal rat ventricles by collagenase dispersion and cultured for 4 days with MCDB 107 medium. A total of $12.5 \times 10^{5}$ myocytes per culture dish was used and the myocytes were incubated at $4^{\circ} \mathrm{C}$ for $6,12,18$, and 24 hours in the various storage solutions. After each incubation time, creatine kinase and lactate dehydrogenase were measured in the storage solutions. The myocytes were then incubated for 24 hours at $37^{\circ} \mathrm{C}$ to evaluate the recovery of the myocyte beating rate. In the MCDB 107 group $(n=7)$, the recovery ratio of myocyte beating rate was complete by 12 hours, then decreased to $44.8 \%$ of control (beating rate before hypothermic incubation) at 24 hours. The saline, Euro-Collins, and University of Wisconsin groups ( $n=7$ each) had significantly lower recovery ratios than the MCDB 107 group (at 12 hours: $61.0 \%, 32.2 \%$, and $48.9 \%$; at 18 hours: $0.0 \%, 5.5 \%$, and $15.1 \%$ of control, respectively). Release of creatine kinase and lactate dehydrogenase in the MCDB 107 group gradually increased and at 24 hours was $143.2 \mathrm{mIU} /$ flask and $486.2 \mathrm{mIU} /$ flask, respectively. However, the saline and University of Wisconsin groups had significantly increased creatine kinase and lactate dehydrogenase values at 24 hours (creatine kinase: 334.6 and $319.6 \mathrm{mIU} /$ flask; lactate dehydrogenase: 821.6 and $654.4 \mathrm{mIU}$ / flask, respectively). The Euro-Collins group showed the greatest increase in both markers (creatine kinase: 1587.5 , lactate dehydrogenase: $2106.9 \mathrm{mIU} /$ flask). In summary, saline and University of Wisconsin solutions showed a beneficial effect on recovery of myocyte viability at $\mathbf{1 2}$ hours compared with Euro-Collins solution, however MCDB 107 medium had the best overall protective effect on cultured myocytes. Accordingly, alternate hypothermic storage solutions, such as cell-culture medium, may have protective characteristics that are suitable for cardiac preservation. (J THORAC CARDIOvasC SURG 1994;107:226-32)

Hiroyuki Orita, MD, Manabu Fukasawa, MD, Shigeki Hirooka, MD, Hideaki Uchino, MD, Kana Fukui, MD, Minoru Kohi, MD, and Masahiko Washio, MD, Yamagata City, Japan

\footnotetext{
$I$ ervation or storage of the donor heart is one of the most

From the Second Department of Surgery, Yamagata University School of Medicine, Yamagata City, Japan.

Supported by a grant from the National Education Ministry.

Received for publication Dec. 22, 1992

Accepted for publication March 30, 1993.

Address for reprints: Hiroyuki Orita, MD, The Second Department of Surgery, Yamagata University School of Medicine, Iida-nishi, Yamagata City, 990-23, Japan.

Copyright ${ }^{(} 1994$ by Mosby-Year Book, Inc.

$0022-5223 / 94 \$ 1.00+.10 \quad 12 / 1 / 48812$
}

important steps to maintain cardiac function because of its exposure to severe hypothermic and ischemic conditions. Recently, the donor heart in transplantation has been preserved under hypothermic and aerobic conditions in an attempt to prolong the preservation time. ${ }^{1,2}$ Moreover, although several groups have investigated the longterm preservation of adult myocardium, ${ }^{1-4}$ there have also been a few reports on immature myocardium, which may be inherently more resistant to ischemia than adult myocardium. ${ }^{5-7}$ The purpose of the present study was to evaluate immature cardiac myocyte viability under hypothermic conditions with four types of storage solutions: saline solution (SS), Euro-Collins solution (ECS), Uni- 


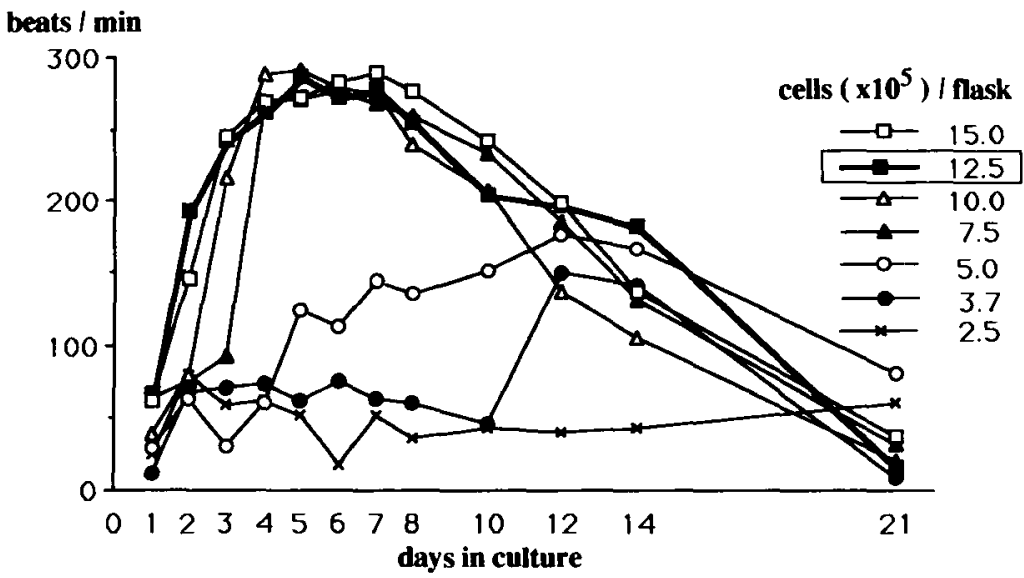

Fig. 1. Cardiac myocyte beating rate associated with various plating densities. Each data point represents geometric mean of five experiments.

versity of Wisconsin solution (UWS), and MCDB 107 medium (MM).

\section{Materials and methods}

Isolation of cardiac myocytes. Cardiac myocytes were prepared from neonatal rat ventricles with a modified Klein's method. ${ }^{8-11}$ Hearts were removed from 1- to 2-day-old neonatal Wistar male rats after decapitation. The ventricles from 20 hearts were minced into fine fragments with scissors in 0.025 $\mathrm{mol} / \mathrm{L}$ HEPES-buffered minimum salt solution (MSS; Gibco, Grand Island, N.Y.). The fragments were rinsed twice with MSS to remove contaminating red blood cells and placed in a $50 \mathrm{ml}$ flask containing $10 \mathrm{ml}$ of $0.1 \%$ collagenase (Wako Chemical, Tokyo) in MSS. The flask was gently agitated for 60 minutes at $37^{\circ} \mathrm{C}$. The enzyme digest was centrifuged at 1000 $g$ for 2 minutes and the pellet washed twice with MSS. The resuspended cells and small aggregates were gently passed through a $90 \mu \mathrm{m}$ wire-mesh screen to remove large aggregates and debris. The cellular filtrate was suspended in $0.025 \mathrm{~mol} / \mathrm{L}$ HEPES-buffered MCDB 107 medium (Kyokuto Pharmaceutical, Tokyo) containing 5\% fetal calf serum (Flow Labs, Rockville, $\mathrm{Md}$.) and placed in a $75 \mathrm{~cm}^{2}$ tissue culture flask, which was incubated for 60 minutes at $37^{\circ} \mathrm{C}$ in a humidified atmosphere of $5 \% \mathrm{CO}_{2}: 95 \%$ air. After incubation, unattached cells were decanted, centrifuged, and rinsed twice with MSS, after which the cell pellet was resuspended in MCDB 107 containing 2\% fetal calf serum, transferrin $10 \mu \mathrm{g} / \mathrm{ml}$ (Sigma, St. Louis, Mo.), and insulin $10 \mu \mathrm{g} / \mathrm{ml}$ (Sigma). The resulting myocytes (>95\%) were gently passed through a $28 \mu \mathrm{m}$ wire-mesh screen. ${ }^{9-14}$ Myocytes were identified by their beating activity, which began on the first day of culture.

Cardiac myocyte hypothermic incubation. Cardiac myocytes were cultured in $25 \mathrm{~cm}^{2}$ flasks that had been previously treated with fibronectin (Wako Chemical, Tokyo). Fibronectin treatment was done by adding $1 \mathrm{ml} \mathrm{of} 10 \mu \mathrm{g} / \mathrm{ml}$ fibronectin in phosphate buffer saline, $\mathrm{pH} 7.4$, to each culture flask and incubating at room temperature for 1 hour before the addition of myocytes. The unbound fibronectin was decanted immediately before the myocytes were added. Thereafter, cell cultures were maintained at $37^{\circ} \mathrm{C}$ in a humidified atmosphere of $5 \%$
Table I. Composition of various storage solutions*

\begin{tabular}{|c|c|c|c|c|}
\hline Component & $S S$ & $E C S$ & $U W S$ & $M M$ \\
\hline $\mathrm{Na}^{+}$ & 154 & 10 & 30 & 115.5 \\
\hline $\mathrm{K}^{+}$ & - & 114 & 125 & 5 \\
\hline $\mathrm{Mg}^{2+}$ & - & 5 & 5 & 1 \\
\hline $\mathrm{Ca}^{2+}$ & - & 0.025 & - & 1 \\
\hline $\mathrm{Cl}^{-}$ & 154 & 15 & - & 119 \\
\hline Phosphate & - & 57.5 & 25 & 3 \\
\hline $\mathrm{HCO}_{3}^{-}$ & - & 10 & - & - \\
\hline $\mathrm{SO}_{4}^{-}$ & - & 5 & 5 & 3 \\
\hline Glucose & - & 139 & - & 4 \\
\hline Lactobionate & - & - & 100 & - \\
\hline Raffinose & - & - & 30 & - \\
\hline Allopurinol & - & - & 1 & - \\
\hline Adenosine & - & - & 5 & - \\
\hline Glutathione & - & - & 3 & - \\
\hline Pentastarch (\%) & - & - & 5 & - \\
\hline Glutamine & - & - & - & 2.5 \\
\hline Other amino acids & - & - & - & 2.4 \\
\hline Vitamins & - & - & - & 0.05 \\
\hline Insulin $(\mathrm{mg} / \mathrm{L})$ & - & - & - & 10 \\
\hline Transferrin $(\mathrm{mg} / \mathrm{L})$ & - & - & - & 10 \\
\hline HEPES buffer & - & - & - & 25 \\
\hline Others & - & - & - & 0.2 \\
\hline
\end{tabular}

*Concentrations are given in $\mathrm{mmol} / \mathrm{L}$, unless otherwise indicated.

$\mathrm{CO}_{2}: 95 \%$ air and the media was changed daily. A myocyte concentration of $2.5 \times 10^{5}$ cells $/ \mathrm{ml}$ was chosen and the total number of cells per flask was $12.5 \times 10^{5} .10,11 \mathrm{On}$ the fourth day of culture when the myocyte beating rate had become stable (Fig. 1), the myocytes were incubated at a $4^{\circ} \mathrm{C}$ hypothermic atmosphere of $5 \% \mathrm{CO}_{2}: 95 \%$ air for $6,12,18$, and 24 hours in the four types of storage solutions (Table I). After each hypothermic incubation, the media was changed and the myocytes were incubated at $37^{\circ} \mathrm{C}$ for an additional 24 hours in a humidified atmosphere of $5 \% \mathrm{CO}_{2}: 95 \%$ air. Triplicate flasks were evaluated for each group and the experiment was repeated an additional six times. All animals received humane care in com- 


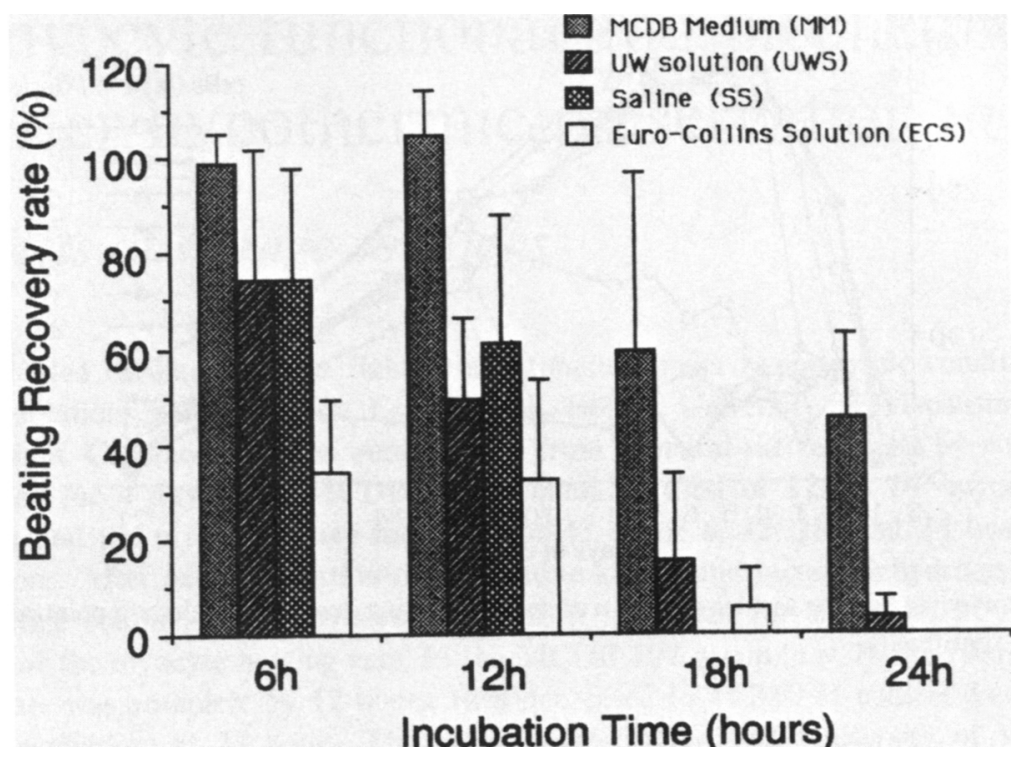

Fig. 2. Recovery ratio of myocyte beating rate measured 24 hours after various hypothermic incubation times ( 6 , 12,18 , and 24 hours) at $4^{\circ} \mathrm{C}$ with four types of storage solutions: SS, ECS, UWS, and MM. Each value is expressed as percentage of control (i.e., beating rate before hypothermic incubation) and represents mean plus or minus standard deviation of seven experiments. Significant differences of each group are as follows: 6 hours: MM versus UWS, $p<0.05$; SS versus ECS, $p<0.005 ; 12$ hours: MM versus UWS and SS, $p<0.001$ and 0.005 ; ECS versus UWS and SS, $p<0.05 ; 18$ hours: MM versus UWS, $p<0.02 ; 24$ hours: MM versus UWS, $p<0.001$.

pliance with the "Principles of Laboratory Animal Care" formulated by the National Society for Medical Research and the "Guide for the Care and Use of Laboratory Animals" prepared by the Institute of Laboratory Animal Resources and published by the National Institutes of Health (NIH Publication No. 86-23, revised 1985).

Cardiac myocyte beating rate recovery after hypothermic incubation. The contraction rate of each flask was observed and the mean contraction or beating rate of 10 myocytes/culture flask determined microscopically. The myocyte beating rate was observed before and 24 hours after hypothermic incubation, and the recovery ratio of the myocyte beating rate was expressed as a percentage of the control, which was determined as the beating rate before hypothermic incubation.

Creatine phosphokinase and lactate dehydrogenase release from cardiac myocytes after hypothermic incubation. After each hypothermic incubation time, creatine kinase (CK) and lactate dehydrogenase (LDH) released from cultured cells were measured spectrophotometrically by CK or LDH assay kits (Unikitrate CK or LDH, Chugai Inc., Tokyo) and a spectrophotometer (RaBA 3030, Chugai Inc., Tokyo). The values of $C K$ and $L D H$ are expressed in international units per culture flask.

Statistical analysis. Data were initially evaluated by rankit analysis to determine the distribution, then by the KruskalWallis one-way analysis of variance to examine the differences within each group, followed by the Mann-Whitney U test. ${ }^{15}, 16$ Results are presented as the mean plus or minus standard deviation, and differences were considered significant if the $p$ value was less than 0.05 .

\section{Results}

Cardiac myocyte beating rate recovery after hypothermic incubation. The myocyte beating rate just before hypothermic incubation was $256.8 \pm 20.2$ beats/ min with a range of $245.2 \pm 24.6$ to $263.7 \pm 27.8$ beats/min for all the groups. In group MM, the myocyte beating rate was complete after 12 hours of incubation ( 6 hours: $99.2 \% \pm 6.3 \% ; 12$ hours: $104.6 \% \pm 9.4 \%$ ), then decreased to $44.8 \% \pm 17.9 \%$ at 24 hours of incubation. However, the UWS, SS, and ECS groups had significantly lower recovery ratios than group MM at 6 hours of incubation $(74.6 \% \pm 27.5 \%, p<0.05 ; 74.3 \% \pm$ $23.7 \%, p<0.02 ; 34.0 \% \pm 15.3 \%, p<0.001$, respectively) and at 12 hours $(48.9 \% \pm 17.4 \%, p<0.001$; $61.0 \% \pm 27.0 \%, p<0.005 ; 32.2 \% \pm 21.3 \%, p<0.001$, respectively). Thereafter, the recovery ratios in groups UWS, ECS, and SS decreased to $15.1 \% \pm 18.1$, $5.5 \% \pm 8.0 \%$, and $0.0 \%$ at 18 hours of incubation, respectively. In addition, groups UWS and SS showed a significantly higher beating recovery than group ECS by 12 hours of incubation ( 6 hours: $p<0.005,12$ hours: $p<0.05$ ). There were no significant differences between groups UWS and SS by 12 hours of incubation although at 18 hours, group UWS showed a low but detectable beating rate (Fig. 2). 


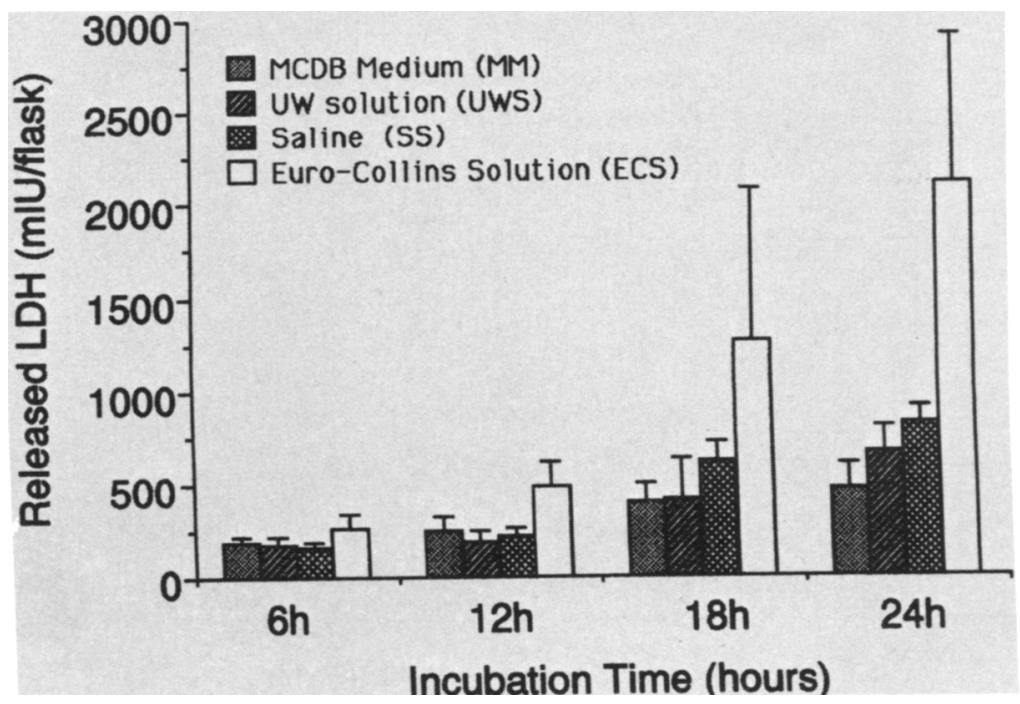

Fig. 3. $\mathrm{CK}$ levels in incubation medium after various hypothermic incubation times at $4^{\circ} \mathrm{C}$ with four types of storage solutions. Each value represents mean plus or minus standard deviation of seven experiments. Significant differences of each group are as follows: 6 and 12 hours: ECS versus MM, SS, and UWS, $p<0.001 ; 18$ hours: ECS versus SS, $p<0.02$, MM and UWS, $p<0.001 ; 24$ hours: MM versus SS and UWS, $p<0.005$, ECS versus MM, SS, and UWS, $p<0.001$.

\section{CK and LDH release from cardiac myocytes after} hypothermic incubation. Before the culture media were exchanged for hypothermic storage, baseline media levels of $\mathrm{CK}$ and $\mathrm{LDH}$ for the previous 24 hours were examined and found to be similar in all groups (group MM: $11.5 \pm 4.5 \mathrm{mIU} /$ flask and $174.7 \pm 25.6 \mathrm{mIU} /$ flask; group UWS: $10.3 \pm 4.4$ and $170.2 \pm 23.9$; group SS: $11.5 \pm 5.4$ and $162.6 \pm 20.4$; group ECS: $12.3 \pm 7.1$ and $187.1 \pm 32.4$, respectively). In group $\mathrm{MM}$, the release of $\mathrm{CK}$ from cardiac myocytes after hypothermic incubation at $4^{\circ} \mathrm{C}$ showed a gradual increase over 24 hours ( 6 hours: $15.9 \pm 14.1 \mathrm{mIU} /$ flask; 12 hours: $49.1 \pm 21.3$; 18 hours: $153.0 \pm 107.4 ; 24$ hours: $143.1 \pm 82.4$ ). In contrast, groups UWS and SS had significantly increased CK values at 24 hours of incubation compared with those in group $\mathrm{MM}$ $(319.0 \pm 80.2 \mathrm{mIU} /$ flask, $p<0.005 ; 334.6 \pm 99.3$ $\mathrm{mIU} /$ flask, $p<0.005$, respectively). Moreover, group ECS showed the greatest CK levels, and these increased significantly beginning at 6 hours of incubation ( 6 hours: $100.7 \pm 36.5 \mathrm{mIU} /$ flask, $\quad p<0.001 ; 12$ hours: $313.6 \pm 125.7, p<0.001 ; 18$ hours: $918.6 \pm 655.2$, $p<0.02$; 24 hours: $1587.5 \pm 676.2, p<0.001$ versus group SS; Fig. 3). There were no significant differences between groups UWS and SS at 24 hours of incubation.

LDH release from group MM cardiac myocytes after hypothermic incubation showed a gradual increase over 24 hours (6 hours: $191.3 \pm 31.2 \mathrm{mIU} /$ flask; 12 hours:
$246.7 \pm 69.4 ; \quad 18$ hours: $395.6 \pm 97.3 ; 24$ hours: $468.2 \pm 126.9$ ). In contrast, group SS showed significantly increased LDH levels at 18 and 24 hours of incubation $(617.5 \pm 92.2 \mathrm{mIU} /$ flask, $p<0.005 ; 821.6 \pm$ $92.0, p<0.001$, respectively) as did group UWS at 24 hours $(654.4 \pm 151.2 \mathrm{mIU} /$ flask, $p<0.05)$ compared with group MM. Moreover, group ECS showed the highest LDH levels, which increased significantly above normal levels after 6 hours of incubation ( 6 hours: $268.6 \pm 68.1 \mathrm{mIU} /$ flask, $p<0.01 ; 12$ hours: $487.7 \pm$ $122.4, p<0.001 ; 18$ hours: $1259.4 \pm 824.5, p<0.05 ; 24$ hours: $2106.9 \pm 807.5, p<0.005$ versus group SS). In addition, group UWS released significantly less LDH than group SS at 18 and 24 hours of incubation $(414.5 \pm 220.4 \mathrm{mIU} /$ flask, $p<0.05 ; 654.4 \pm 151.2$, $p<0.05$, respectively; Fig. 4).

Mortality of cardiac myocytes after hypothermic incubation. At 24 hours after hypothermic incubation at $4^{\circ} \mathrm{C}$, myocytes in group MM showed minor morphologic changes compared with the control myocytes (that is, myocytes before hypothermic incubation) with a mortality rate of $4.8 \% \pm 1.9 \%$ as determined by trypan blue exclusion test. In contrast, group UWS myocytes showed major morphologic changes that included cellular atrophy, degeneration, and peeling off the bottom of the culture flasks. The UWS group mortality rate was $67.5 \% \pm 22.1 \%$. Moreover, marked morphologic changes were observed in groups SS and ECS, in which most 


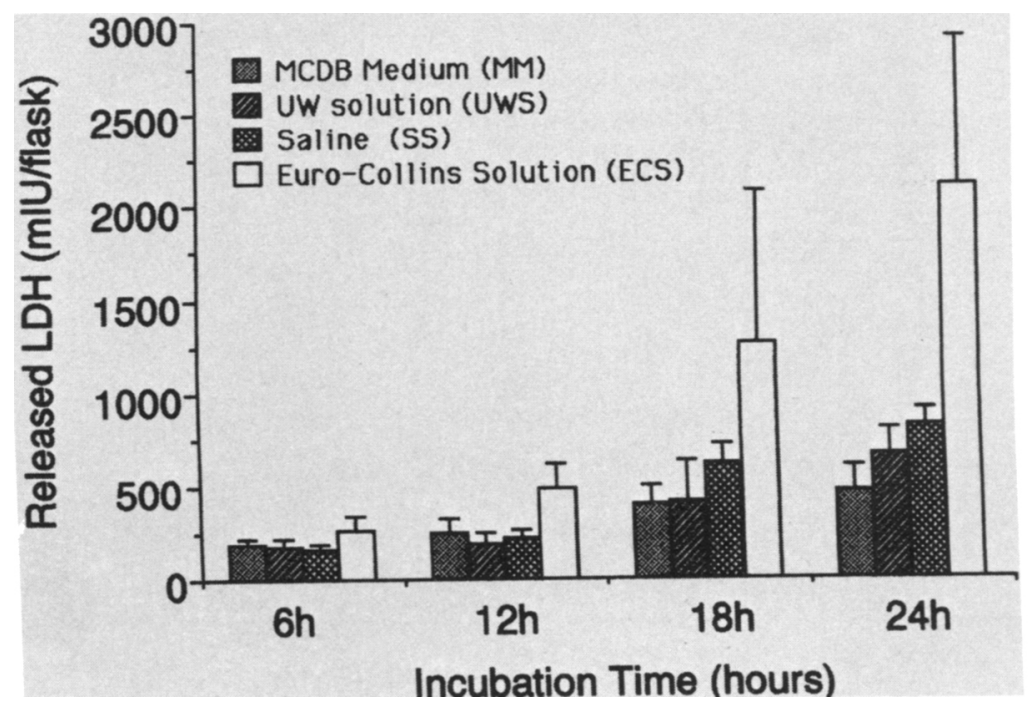

Fig. 4. LDH levels in incubation medium after various hypothermic incubation times at $4^{\circ} \mathrm{C}$ with four types of storage solutions. Each value represents mean plus or minus standard deviation of seven experiments. Significant differences of each group are as follows: 6 hours: ECS versus MM, SS, and UWS, $p<0.01$; 12 hours: ECS versus MM, SS, and UWS, $p<0.001 ; 18$ hours: MM versus SS, $p<0.005$, UWS versus SS, $p<0.05$, ECS versus MM, SS, and UWS, $p<0.05 ; 24$ hours: MM versus UWS and SS, $p<0.05,0.001$, UWS versus $\mathrm{SS}, p<0.005$, ECS versus SS, $p<0.005, \mathrm{MM}$, and UWS, 0.001 .

of the myocytes were dead by trypan blue exclusion test after 24 hours (>95\% mortality).

\section{Discussion}

Cardiac myocytes isolated from neonatal rat ventricles formed confluent monolayers by the fourth day of culture, at which time they almost all beat synchronously and steadily at a constant frequency that was maintained for 5 days of culture, after which it gradually decreased over 21 days. These observations were consistent for cell concentrations equal to or greater than $7.5 \times 10^{5}$ myocytes/ culture flask. However, cell densities less than $7.5 \times 10^{5}$ myocytes/culture flask showed erratic behavior in culture (Fig. 1). Accordingly, in this study, we used myocytes on the fourth day of culture at a concentration of $12.5 \times 10^{5}$ myocytes/culture flask. In addition, the myocytes did not beat, or beat weakly, just after hypothermic incubation. However, almost all the myocytes showed a synchronous and steady beating by 24 hours after hypothermic incubation. Therefore we evaluated the myocyte beating rate recovery at this time. ${ }^{10,11}$

Myocardial hypothermia has been used routinely in cardiac operations, especially in neonates or during heart transplantation. Recently, the donor heart has been preserved in various crystalloid storage solutions under hypothermic and aerobic conditions in an attempt to prolong preservation time. ${ }^{1,2,17,18}$ Protection against hypo- thermic cellular injury therefore becomes an important issue in evaluating cardiac preservation. In this study, we evaluated the functional and biochemical response of immature rat cardiac myocytes cultured in either ECS, UWS, MM, or SS. The MM has been shown to be an excellent medium for immature myocytes cultured under serum-free conditions ${ }^{9-11}$ and as used here provided complete protection from hypothermic injury after 12 hours at $4^{\circ} \mathrm{C}$. However, a decline in myocyte functional activity, measured as percent recovery of beating rate 24 hours after hypothermic incubation, became apparent after 18 hours when myocytes showed a $59 \%$ recovery of the beating rate. In contrast, the UWS, SS and ECS groups had significantly lower recovery ratios after 6 hours of hypothermic incubation. In addition, UWS and SS showed better beating rate recovery than ECS by 12 hours, after which time UWS exhibited a low but detectable beating rate. The evaluation of myocytes by beating rate recovery, as opposed to the more comprehensive contractility measurements, may not accurately reflect all parameters of myocyte function, but appears to have utility after short durations under hypothermic conditions. ${ }^{10,11,19}$ However, further validation with regard to the contractility will be necessary. We consider that the measurement of myocyte contractile ratio with an imageanalyzing system may be a useful parameter of the contractility or function. 
Cellular release of the biochemical markers CK and LDH was significantly elevated after 18 hours in the MM, UWS, and SS groups, whereas the ECS group showed the greatest increases beginning at 6 hours of hypothermic incubation. In addition, the UWS group showed lower LDH levels than the SS group after 18 hours. These two cytoplasmic enzymes have been shown to increase linearly with culture time and are indicative of cellular damage to cultured cells. ${ }^{12,20,21}$ Thus the MM provided the best protection both functionally and biochemically among the four solutions tested. Also, UWS and SS had better protective effects on myocytes than ECS.

SS and ECS are commonly used preparations for donor-organ preservation. Most transplant centers use similar techniques for heart storage consisting of a cold cardioplegic arrest and immersion in saline ice solution for transportation..$^{22-24}$ In addition, ECS, which contains electrolytes similar to intracellular fluid, ${ }^{25}$ has been shown to be suitable for donor heart preservation and to be superior to SS, which mimics the major component of extracellular fluid. ${ }^{17,18,26,27}$ However, Swanson et al. ${ }^{28}$ suggested that cardiac muscles stored in ECS recover more slowly than those in extracellular solution such as SS. Recently, UWS has been used; this solution has properties of intracellular fluid and contains impermeants to prevent cell swelling (lactobionic acid and raffinose), melitose, adenosine, the antioxidant glutathione, and allopurinol. ${ }^{29}$ Fremes et al. ${ }^{18}$ and Schmit et al. ${ }^{30}$ demonstrated that UWS better preserved myocyte morphology and maintained a higher intracellular adenosine triphosphate content than ECS after 24 hours of storage. In this study, myocytes incubated in ECS showed marked cellular injury compared with results using SS and UWS. In addition, UWS showed no superior protective effects compared with SS after 12 hours of storage and severe cellular damage was observed after 24-hour storage even though UWS contains many types of protective additives. Therefore it was postulated that the storage solutions having properties of intracellular fluid may be injurious to immature myocardium under hypothermic conditions.

Also, it has been reported that phosphate buffer, which is included in ECS and UWS, may have a toxic effect on immature myocytes. ${ }^{19}$ On the other hand, MM showed an excellent protective effect on immature myocyte viability under hypothermic preservation. The MM, which is similar to extracellular fluid, includes glucose, amino acids, insulin, and transferrin and is buffered with HEPES. Although Hendry et al. ${ }^{17}$ suggested that additives such as amino acids, insulin, and vitamins should not be useful for long-term preservation, such additives may be effective in preserving immature myocardium under hypothermic conditions. Additionally, HEPES buffer has been shown to have good buffering capacity and to be less cytotoxic than phosphate buffer. ${ }^{19,31}$ Accordingly, the observed beneficial effects of MM may be attributed to its extracellular fluid qualities, HEPES buffer, insulin, transferrin, and nutrient additives. In addition, the effects may be mediated by mechanisms of sarcoplasmic metabolic preservation or stabilization of sarcolemma. Extracellular fluid qualities, insulin, and transferin may stabilize sarcolemma, and HEPES buffer, insulin, transferrin, and nutrient additives may preserve sarcoplasmic metabolism.

In summary, the in vitro cell-culture system reported here has the following advantages for evaluating hypothermic preservation: (1) ease of observation and measurement of biochemical responses to treatments such as storage solutions or cytoprotective agents; (2) maintenance of a well-defined biochemical and physical environment; and (3) ability to evaluate multiple treatments in a single experiment. Furthermore, although other cellculture systems have been used with moderate success, ${ }^{21}, 30$ this procedure provides a well-defined and purified myocyte-culture system as a useful model to evaluate the direct effects on myocytes, not affected by other cell components such as endothelial cells and fibroblasts, ${ }^{11}$ of various environmental or chemical stimulation including ischemic or postischemic reperfused conditions.

We thank Mr. Joseph D. Campeau for his assistance in the preparation of this manuscript.

\section{R E F E R E N C ES}

1. Burt JM, Copeland JG. Myocardial function after preservation for 24 hours. J ThORAC Cardiovasc Surg 1986;92:238-46.

2. Takahashi A, Braimbridge MV, Hearse DJ, Chambers DJ. Long-term preservation of the mammalian myocardium: effect of storage medium and temperature on the vulnerability to tissue injury. J ThORAC CardiovasC Surg 1991; 102:235-44.

3. Wicomb W, Cooper DKC, Hassoulas J, Rose AG, Barnard CN. Orthotopic transplantation of the baboon heart after 20 to 24 hours' preservation by continuous hypothermic perfusion with an oxygenated hyperosmolar solution. $\mathbf{J}$ Thorac Cardiovasc Surg 1982;83:133-40.

4. Warner M, Guerraty A, Alivizatos P, et al. Assessment of myocardial subcellular function after 24 hours of in vitro preservation and transplantation. J THORAC CARDIOVASC SURG 1982;83:290-7.

5. Jarmakani JM, Nakazawa M, Nagatomo T, Langer GA. Effect of hypoxia on mechanical function in the neonatal mammalian heart. Am J Physiol 1978;235:H469-74.

6. Bove EL, Gallagher KP, Drake DH, et al. The effect of hypothermic ischemia on recovery of left ventricular func- 
tion and preload reserve in the neonatal heart. J THORAC Cardiovasc Surg 1988;95:814-8.

7. Grice WN, Konishi T, Apstein CS. Resistance of neonatal myocardium to injury during normothermic and hypothermic ischemic arrest and reperfusion. Circulation 1987;76 (suppl V):V-150-5.

8. Klein I, Daood M. Regulation of the growth of nonmuscle heart cells in culture. In Vitro Cell Dev Biol 1985;21:6936.

9. Suzuki T, Ohta M, Hoshi H. Serum-free, chemically defined medium to evaluate the direct effects of growth factors and inhibitors on proliferation and function of neonatal rat cardiac muscle cells in culture. In Vitro Cell Dev Biol 1989;25:601-6.

10. Orita H, Fukasawa M, Hirooka S, Fukui K, Kohi M, Washio M. A cardiac myocyte culture system as an in vitro experimental model for the evaluation of hypothermic preservation. Surg Today 1993;23:439-43.

11. Orita H, Fukasawa M, Hirooka S, Fukui K, Kohi M, Washio M. Protection of cardiac myocytes from hypothermic injury by cardiac fibroblasts isolated from neonatal rat ventricle. J Surg Res 1993;23:439-43.

12. Blondel B, Roijen I, Cheneval JP. Heart cells in culture: a simple method for increasing the population of myoblasts. Experientia 1971;27:356-8.

13. Polinger IS. Separation of cell types in embryonic heart cell culture. Exp Cell Res 1970;63:78-82.

14. Yagev S, Heller M, Pinson A. Change in cytoplasmic and lysosomal enzyme activities in cultured rat heart cells: the relationship to cell differentiation and cell population in culture. In Vitro 1984;20:893-8.

15. Siegel S, Castellan NJ Jr. The Kruskal-Wallis one-way analysis of variance by ranks. In: Anker JD, ed. Nonparametric statistics for the behavioral sciences. New York: McGraw-Hill, 1988:206-16.

16. Siegel S, Castellan NJ Jr. The Wilcoxon-Mann-Whitney test. In: Anker JD, ed. Nonparametric statistics for the behavioral sciences. New York: McGraw-Hill, 1988:12837.

17. Hendry PJ, Labow RS, Barry TA, Keon WJ. An assessment of crystalloid solutions for donor heart preservation. J THORAC CARDIOvASC SURG 1991;101:833-8.

18. Fremes SE, Li RK, Weisel RD, Mickle DAG, Tumiati LC. Prolonged hypothermic cardiac storage with University of Wisconsin solution: an assessment with human cell culture. J THORAC CARDIOVASC SURG 1991;102:666-72.

19. Goshima K. A study on the preservation of the beating rhythm of single myocardial cells in vitro. Exp Cell Res 1973;80:432-8.

20. Laarae AVD, Hollaar L, Kokshoorn LJM, Witteveen SAGJ. The activity of cardio-specific isoenzymes of creatine phosphokinase and lactate dehydrogenase in monolayer cultures of neonatal rat heart cells. J Mol Cell Cardiol 1979;11:501-10.

21. Acosta D, Puckett M, McMillin R. Ischemic myocardial injury in cultured heart cells: leakage of cytoplasmic enzymes from injured cells. In Vitro 1978;14:728-32.

22. Billingham ME, Baumgartner WA, Watson, et al..Distant heart procurement for human transplantation. Circulation 1980;62(suppl I):11-9.

23. Emery RW, Cork RC, Levinson MM, et al. The cardiac donor: a six-year experience. Ann Thorac Surg 1986;41: 356-62.

24. Davis RA, Koshal A, Walley V. Temporary diastolic noncompliance with preserved systolic function after heart transplantation. Transplant Proc 1987;19:3444-7.

25. Collins GM, Bravo-Shugarman M, Terasaki PI. Kidney preservation for transplantation. Lancet 1969;2:1219-22.

26. Toledo-Pereya LH, Sharp HL, Condie RM, Chee M, Lillehei RC, Najarian JS. Preservation of canine hearts after warm ischemia (zero to thirty minutes) and one to two days of hypothermic storage: a comparative analysis of crystalloid and colloid solutions with different osmolarity and ion composition. J Thorac Cardiovasc SurG 1977;74;594-603.

27. McGregor CGA, Hannan J, Smith AF, Muir AL, Wheatley DJ. A study of cold cardioplegic myocardial protection in rats: an experimental model using the uptake of technesium 99 pyrophosphate and enzyme activity as parameters of injury. Cardiovasc Res 1983;17:70-4.

28. Swanson DK, Dufek JH, Lahn DR. Left ventricular function after preserving the heart for 2 hours at $15^{\circ} \mathrm{C}$. J THORaC Cardiovasc Surg 1980;79:755-60.

29. Wahlberg JA, Love R, Landegaard L, Southard JH, Belzer FO. 72 hour preservation of the canine pancreas. Transplantation 1987;43:5-8.

30. Schmid T, Landry G, Fields BL, Belzer FO, Haworth RA, Southard JH. The use of myocytes as a model for developing successful heart preservation solutions. Transplantation 1991;52:20-6.

31. Good NE, Winget GD, Winter W, Connolly TN, Izawa S, Singh RMM. Hydrogen ion buffers for biological research. Biochemistry 1966;5:467-77. 